6.

Derecho administrativo 

Revista de Derecho

de la Pontificia Universidad Católica de Valparaíso XXXIII (Valparaíso, Chile, ${ }^{\text {do }}$ Semestre de 2009)

[pp. 429 - 452]

\title{
LA POTESTAD SANCIONADORA DE LAS EMPRESAS DE SERVICIOS PÚBLICOS DOMICILIARIOS Y SU CONSTITUCIONALIDAD. EL CASO DE COLOMBIA*
}

["The Sanctioning Legal Authority of the House Public Services Companies and its Constitutionality the Case of Colombia"]

\author{
María Lourdes Ramírez TorRado** \\ Universidad del Norte, Barranquilla, Colombia \\ Judith ECheverRía Molina*** \\ Universidad del Norte, Barranquilla, Colombia
}

\section{RESUMEN}

Este artículo analiza el tema relativo con las prerrogativas entregadas a las empresas prestadoras de servicios públicos domiciliarios, y de modo concreto se aborda lo concerniente con la potestad sancionadora y las sanciones administrativas impuestas por estas entidades. De este modo, el objetivo principal es determinar si el marco jurídico actual permite que las instituciones que gestionan esta actividad puedan ejercer una

\section{ABSTRACT}

This article analyzes the topic related to prerogatives granted to the domiciliary public service provider companies and in a concrete way we deal with the administrative sanctions imposed to these entities. This way, the main objective is to determine if the current legal frame allows the institutions which develop this activity can act with a punitive potesty within the constitutional frame. To reach this objective the norms, the sentences

* Este artículo es resultado de una investigación ejecutada en el marco del proyecto titulado: "Potestad sancionadora de la Administración en Colombia", que financia la Universidad del Norte, y dirige la profesora Dra. María Lourdes Ramírez Torrado.

** Profesora investigadora, adscrita al Grupo de Investigación en Derecho y Ciencia Política (GIDECP), de la Universidad del Norte. Dirección postal: Universidad del Norte, Km. 5, vía a Puerto Colombia, A.A. 1569, Barranquilla, Colombia. Correo electrónico: torradom@uninorte.edu.co

*** Profesora investigadora adscrita al grupo de investigación en Derecho y Ciencia Política (GIDECP) de la Universidad del Norte. Dirección postal: Universidad del Norte, Km. 5, vía a Puerto Colombia, A.A. 1569, Barranquilla, Colombia Correo electrónico: jechever@uninorte.edu.co. 
potestad punitiva dentro del marco constitucional. Para alcanzar este objetivo se revisaron las normas, sentencias, y la doctrina tanto nacional como extranjera que han estudiado la cuestión.

Palabras Clave: Sanciones administrativas - Servicios públicos - Legalidad - Igualdad. and the doctrine at national and foreign level which have studied this topic were revised.

KEYWORDS: Administrative sanctions - Public services, - Legality - Equality.

\section{INTRODUCCIÓN}

La Constitución de 1991 introdujo una transformación radical en el ámbito de los servicios públicos domiciliarios. Este cambio se concretó claramente en la Ley No 142/1994, que se ha convertido en la columna vertebral de la actividad.

En el cuerpo de esta normativa se han contemplado varias cuestiones novedosas como ha sido la autorización a los particulares de prestar servicios públicos domiciliarios; y de igual modo se han consagrado una serie de facultades a las entidades prestadoras para que presten un mejor servicio. Ello se traduce en la posibilidad de imponer servidumbres; la competencia para expedir actos administrativos; o lo propio con la aplicación de las cláusulas exorbitantes.

Sin embargo, esta investigación se centra en responder el interrogante que se ha venido planteando desde hace algunos años, y que no ha tenido una respuesta por parte de la doctrina, relativo con viabilidad constitucional que las empresas de servicios públicos domiciliarios impongan sanciones a los usuarios por el incumplimiento de las obligaciones previstas en los contratos de prestaciones uniformes.

\section{PANORAMA DE LOS SERVICIOS PÚBLICOS DOMICILIARIOS ANTES DE LA “CONSTITUCIÓN” DE 1991}

Antes de la Constitución de 1991, el panorama de los servicios públicos domiciliarios $^{1}$ en el país se caracterizaba por una cobertura escasa, baja calidad de los servicios suministrados y un rezago en la gestión comercial de los entes prestatarios de los mismos.

Lo anterior era consecuencia, de una parte por las políticas públicas, donde el Estado era el prestador en exclusiva de estos servicios, bien sea

${ }^{1}$ La ley No 142 de 1994, art. 1, comprende por servicios públicos domiciliarios a: acueducto, alcantarillado, aseo, energía eléctrica, distribución de gas combustible, telefonía fija pública básica conmutada y la telefonía local móvil en el sector rural. 
directamente o a través de empresas públicas. Y de igual modo, por las políticas de financiación y planificación que estaban centralizadas e impedían al usuario y al empresario participar en la planeación, gestión y ejecución de las obras, proyectos y servicios que les afectaba.

A lo expuesto se agrega las acusaciones de corrupción que fueron objeto las empresas de servicios públicos domiciliarios en Colombia ${ }^{2}$, a las que se les acusaba de ser un foco de corrupción, puesto que eran consideradas como espacio propicio para el desarrollo de prácticas electorales; existiendo denuncias frecuentes de intercambio de votos por bajas tarifas.

Como era previsible el escenario planteado generó un grave problema presupuestal y de inequidad, ya que con recursos estatales se mantenían tarifas artificiosamente bajas a todos los sectores de la sociedad; incluyendo a los usuarios industriales y comerciales que no tenían las mismas necesidades de las comunidades menos favorecidas.

El panorama descrito en Colombia era muy semejante al de otros países latinoamericanos los que a través de reformas constitucionales reestructuraron sus estados disminuyendo su intervención económica; dando paso al sector privado y a los flujos de capital internacional. Para el caso colombiano, la gran transformación en el sector tiene lugar a partir de la expedición de la nueva Constitución en 1991 y de la Ley No 142/1994, (denominada "Ley de servicios públicos domiciliarios"), normas que modifican el horizonte de las políticas públicas estatales en materia de servicios públicos domiciliarios.

${ }^{2} \mathrm{Al}$ respecto VARELA BARrios, Edgardo, Las privatizaciones en Cartagena y Barranquilla. Un paradigma mercantilista en la gestión de los servicios públicos domiciliarios en Colombia, en Revista Pensamiento y Gestión 23 (2007) p. 219, describe el panorama reinante en el sector afirmando: "que durante los años 50-80, en Cartagena y Barranquilla las negociaciones de las convenciones colectivas generaron un esquema de amplia favorabilidad en términos de derechos laborales, primordialmente en función del tipo de remuneración salarial establecido en la generosa determinación de políticas pensionales, tanto en montos como en relación con la edad límite, generalmente fijada solamente a partir de los 20 años de trabajo continuo o discontinuo. De igual manera, las convenciones colectivas reconocieron numerosos emolumentos de carácter extralegal, y se carecía de fondos pensionales para la provisión y el pago de éstas. $\mathrm{Al}$ igual que en muchas otras empresas del sector, no existían fondos de pensiones y éstas se pagaban de los ingresos corrientes, con lo cual se generaba una suerte de nómina paralela. Finalmente, las convenciones colectivas igualmente otorgaron un poder significativo de co-administración a los sindicatos en muchos de los asuntos vitales de las compañías, incluyendo aquellos del ingreso del nuevo personal. Estas empresas estructuraban sus nóminas a partir de su parcelación burocrática entre los diversos concejales e, incluso, con una injerencia significativa de los parlamentarios que provenían de dichas regiones".. 


\section{PANORAMA DE LOS SERVICIOS PÚBLICOS DOMICILIARIOS DESPUÉS DE EXPEDIDA LA “CONSTITUCIÓN” DE 1991}

El constituyente de 1991 dedica un título de la nueva Constitución, el doceavo, a establecer los parámetros que regirían los destinos de los servicios públicos domiciliarios. Así las cosas el constituyente primario se ocupó de la liberalización en la gestión de los servicios públicos domiciliarios ${ }^{3}$, el tema tarifario; el otorgamiento de prerrogativas a los prestadores de este tipo de servicios, entre otros aspectos.

De este modo, la Carta política abrió espacios para que personas jurídicas de distinta naturaleza pudieran prestar servicios públicos domiciliarios. Con ello, se autoriza ${ }^{4}$, además de los municipios y las entidades descentralizadas a las organizaciones comunitarias y a las personas naturales o jurídicas para que ofrecieran este servicio. Pero, claro está, el Estado se reservó la facultad de regular, controlar y vigilar a los empresarios de dicha actividad.

Es importante aclarar, que no se niega la posibilidad al Estado para que preste los servicios públicos domiciliarios, pero lo condiciona a que se constituyan sociedades por acciones 5 ; o en su defecto bajo la figura de

${ }^{3}$ Penagos, Gustavo, Empresas estatales. Proyección al siglo XXI (Bogotá, Doctrina y Ley, 2000), p. 21. comprende que las empresas públicas son: "las incorporadas y controladas por el Estado, directamente o por medio de sus "holdings", cualquiera que sea su actividad que desarrolle (con tal que sea actividad económica). cualquiera que sea la forma que adopte (sociedad del Estado, empresa del Estado, sociedad mixta, etc.), y cualquiera que sea la normativa que las discipline (pública o privada)"..

${ }^{4}$ En este caso el artículo contempla que están autorizados para prestar servicios públicos domiciliarios: "15.1. Las empresas de servicios públicos. 15.2. Las personas naturales o jurídicas que produzcan para ellas mismas, o como consecuencia o complemento de su actividad principal, los bienes y servicios propios del objeto de las empresas de servicios públicos. 15.3. Los municipios cuando asuman en forma directa, a través de su administración central, la prestación de los servicios públicos, conforme a lo dispuesto en esta Ley. 15.4. Las organizaciones autorizadas conforme a esta Ley para prestar servicios públicos en municipios menores en zonas rurales y en áreas o zonas urbanas especificas. 15.5. Las entidades autorizadas para prestar servicios públicos durante los periodos de transición previstos en esta Ley.15.6. Las entidades descentralizadas de cualquier orden territorial o nacional que al momento de expedirse esta Ley estén prestando cualquiera de los servicios públicos y se ajusten a lo establecido en el parágrafo del Artículo 17".

${ }^{5}$ Art. 17 Ley No 142 de 1994 afirma: "las empresas de servicios públicos son sociedades por acciones cuyo objeto es la prestación de los servicios públicos de que trata esta Ley, Parágrafo 1o. Las entidades descentralizadas de cualquier orden territorial o nacional, cuyos propietarios no deseen que su capital esté representado en acciones, deberán adoptar la forma de empresa industrial y comercial del Estado".Lo anterior se podría mirar como una apertura para que los particulares pudieran participar en el mercado de los servicios públicos domiciliarios, ya que las sociedades por acciones son el espacio 
empresas industriales o comerciales del Estado ${ }^{6}$.

Otra modificación introducida por la Constitución de 1991 ha sido la implementación de un régimen tarifario que no permite la prestación de servicios públicos domiciliarios de forma gratuita, sino que por el contrario las empresas prestatarias deben ofrecerlo teniendo en cuenta siempre el criterio de costos. Buscando con ello que el Estado no continuara subsidiando totalmente sin focalizar las necesidades y los beneficiarios, con recursos del fisco, la provisión de este tipo de servicios. Y del mismo modo, que la tarifa tuviera como objetivo recuperar los costos económicos asociados con la prestación de los servicios.

De igual manera, la Constitución de 1991 abrió espacios para que la comunidad de manera organizada ejerciera vigilancia y control del sector y estableció que la ley desarrollaría los principios constitucionales y garantizará a los usuarios un régimen que determine sus deberes y derechos. Con esto se abrieron novedosos espacios para la participación de los usuarios en la gestión y fiscalización de las empresas prestatarias de los servicios públicos, lo que se tradujo en la creación de los Comités de Desarrollo y Control Social ${ }^{7}$.

Tanto fue el valor que el constituyente originario entregó al sector objeto de análisis que se prohibió el ejercicio del derecho de huelga en los servicios públicos domiciliarios ${ }^{8}$. Medida que sin duda favorece a los

propicio para lograr la vinculación de socios estratégicos en dichas actividades, hecho que no podría lograrse bajo otra forma societaria. No sobra recordar como las sociedades anónimas son compañías que favorecen la vinculación de capitales de distinta naturaleza y "en la que sus integrantes se comprometen a aportar con el fin de repartirse utilidades obtenidas con motivo de la actividad social, en donde la participación de los asociados se determinan por titulos denominados acciones, cada una de las cuales tiene un valor". (LeAL, Hildebrando, Derecho de sociedades comerciales (Bogotá, Leyer. 2006), 846 pp.

${ }^{6}$ De otra parte, las empresas industriales y comerciales del Estado, en un mercado competitivo actúan en igualdad de condiciones que los particulares, a pesar de las prerrogativas que la ley en mención les ha otorgado. Es decir, se comportan como una empresa más en el desarrollo de su actividad industrial y comercial para la cual fueron creadas. (Art. 87 de la Ley No 489 de 1998). Sin que se les entregue a estas entidades un trato favorable para el desarrollo de sus actividades, ya que las empresas del Estado no tendrán ventajas que les garanticen espacios privilegiados para el desarrollo de sus funciones, frente a los particulares.

${ }^{7}$ Ley No 142 de 1994, en sus artículos 62 a 66, crea los comités de desarrollo y control social de los servicios públicos domiciliaros, como espacios para que la comunidad usuaria ejerciera control, y vigilancia sobre las empresas de servicios públicos que funcionan en Colombia.

${ }^{8}$ La Constitución en su artículo 56 contempla el derecho a la huelga, su texto expresa: "se garantiza el derecho de huelga, salvo en los servicios públicos esenciales definidos por el legislador". 
usuarios finales del servicio en cuanto se les garantiza su continuidad'; y al mismo tiempo brinda espacios de seguridad jurídica a los entes prestatarios, sin importar su naturaleza jurídica.

\section{PRERROGATIVAS OTORGADAS A LOS PRESTADORES DE SERVICIOS PÚBLICOS DOMICILIARIOS POR PARTE DE LA LEGISLACIÓN NACIONAL}

Consecuencia de los objetivos, planteados por el legislador constituyente de 1991 (la liberación del mercado, el impulso de la participación de los entes privados en la operación y gestión de esta actividad, y el cambio en la política tarifaria) se dicta por parte del Congreso de la república la Ley No 142 de 1994. Norma que desarrolla los postulados planteados en la Constitución y entrega una serie de garantías al agente prestador del servicio, independiente del origen capital, para que la prestación del servicio sea más atractiva.

Claro ejemplo de lo expresado es lo relativo con la decisión que las contrataciones que se dan en el seno de estas instituciones, en la mayoría de los supuestos, se rijan por el derecho privado, sin que tenga relevancia la naturaleza del patrimonio. Así se les excluye a las entidades estatales de la obligación, en la mayoría de los supuestos, de someterse a los principios y exigencias legales para contratar, a pesar que los bienes e intereses en juego sean de alcance general y los servicios se consideren esenciales para la comunidad ${ }^{10}$.

Otra muestra de las prerrogativas contempladas en la Ley No 142 de 1994 es lo ocurrido con la facultad que se les reconoce a las entidades prestadoras de servicios públicos domiciliarios para imponer servidumbres. En este sentido, la ley permite que este tipo de empresas sean titulares de garantías especiales para el desarrollo del objeto social, confiriéndoseles la facultad de utilizar el espacio público, ocupar temporalmente bienes inmuebles, o promover la constitución de servidumbres, todo para el desarrollo cabal de sus funciones ${ }^{11}$.

Asimismo, otra de las garantías, que entregó la Ley No 142 a las empresas que gestionan la actividad en análisis es la relativa con la posibilidad de realizar inspecciones a los lugares en donde se presta el servicio ${ }^{12}$. Siendo

${ }^{9}$ Devis Isaac, Aspectos constitucionales de los servicios públicos y las telecomunicaciones en Colombia (Bogotá, Universidad del Rosario, 2007), p. 88.

${ }^{10}$ Ley No 142 de 1994, artículo 32.

${ }^{11}$ Ley No 142 de 1994, artículo 33.

${ }^{12}$ Ley No 142 de 1994, artículo 145. 
posible la realización de visitas a los usuarios con el fin de verificar si existen fraudes que pudiesen generar consumos artificialmente bajos.

Sin embargo, en el asunto que nos cita, el ejercicio de la actividad sancionadora de las entidades que prestan servicios públicos domiciliarios, la ley en mención no realiza una habilitación específica y detallada de esta potestad; sino que por el contrario se limita a establecer que: "para restablecer el servicio, si la suspensión o el corte fueron imputables al suscriptor o usuario, éste debe eliminar su causa, pagar todos los gastos de reinstalación o reconexión en los que la empresa incurra, y satisfacer las demás sanciones previstas, todo de acuerdo a las condiciones uniformes del contrato".

De todos modos, ha sido esta disposición la que ha servido de sustento legal a las entidades para que diseñen infracciones e impongan sanciones en los contratos de prestaciones uniformes; generándose el interrogante si satisface o no las exigencias constitucionales que se demandan en el ejercicio de la actividad sancionadora de estas entidades.

\section{EL PODER SANCIONADOR DE LAS ENTIDADES QUE PRESTAN SERVICIOS PÚBLICOS DOMICILIARIOS}

Por facultad sancionadora se comprende aquel poder que ostentan las autoridades del Estado, sean penales o administrativas, para castigar a las personas cuyas conductas encuadren en lo previsto en el tipo de una infracción administrativa o penal.

Tal como se ha expresado, en el campo de los servicios públicos domiciliarios, uno de los efectos más notorios de la Constitución de 1991 es que se da paso para que los particulares presten este tipo de servicios. Con esta situación se plantea el interrogante si una empresa de capital privado podría imponer sanciones administrativas a sus usuarios, o por el contrario esta prerrogativa es exclusiva del Estado ${ }^{13}$.

${ }^{13}$ El ejercicio de las funciones públicas por particulares consiste en la posibilidad que se le entrega a los particulares para que participen de la gestión de los asuntos administrativos, de acuerdo a lo establecido por la Constitución, la ley y los reglamentos. Resulta oportuno establecer la diferencia entre la atribución de las funciones públicas a particulares y la privatización. La que consiste, de acuerdo a lo establecido por la C-866/1999, en "que un patrimonio de naturaleza pública, es enajenado a particulares, de tal manera que se trueca en privado. La privatización comporta un cambio en la titularidad de ese patrimonio, que siendo estatal, pasa a manos de los particulares, y debe aquella responder a politicas que miran por la realización de los principios de eficiencia y eficacia de la función pública y enmarcarse dentro de los criterios del artículo 60 de la Carta" Sin que ello implique, de acuerdo a lo dispuesto por la C-866/1999, que las autoridades administrativas se desprendan totalmente de las competencias que la autoridad le otorga. El ejercicio de las funciones públicas por parte de parti- 
A esta cuestión contestamos afirmativamente, consecuencia de las

culares obedece entre otras razones a la interrelación que existen entre el Estado y la sociedad civil; dejando a un lado "los moldes formalistas y los criterios herméticos, para dar paso a la concepción material de la cosa pública, a la creciente participación de todos en las decisiones que los afectan, [...], con miras al servicio efectivo de la comunidad, la promoción de la prosperidad general y la garantía de los principios, derechos y deberes consagrados en la Constitución (articulo 20 C.P.)" (C-286/1996). De este modo, la función pública ejercida por particulares se soporta en los principios de solidaridad y participación. Encontrando el sostén constitucional en los mencionados principios, con los que el legislador constituyente extendió los espacios de participación democrática para la toma de decisiones y alcanzar los objetivos relativos con la "satisfacción de las necesidades básicas colectivas y de ampliar la democracia”. (C-866/1999). Así las cosas, la Constitución contempla de forma general y particular la posibilidad que los particulares asuman el ejercicio de funciones públicas. En el primer supuesto tenemos al artículo 123 que establece: "La ley determinará el régimen aplicable a los particulares que temporalmente desempeñen funciones públicas y regulará su ejercicio". O lo propio establecido en el artículo 210 que reza: "Los particulares pueden cumplir funciones administrativas en las condiciones que señale la ley". De modo más particular encontramos las previsiones constitucionales que se refieren directamente a ámbitos en los que los particulares pueden incursionar. Aun cuando algunos de ellos fueron considerados hasta no hace mucho tiempo como inherentes al funcionamiento del Estado. Son los supuestos de: colegios de profesionales (art. $26 \mathrm{CN}$ ); notarios (art. $131 \mathrm{CN}$ ), autoridades indígenas respecto a su comunidad (art. $246 \mathrm{CN}$ ); prestación de los servicios públicos (365 CN); seguridad social (art. 48); servicios de salud (art. 49). O lo propio, no ya con la autorización constitucional, sino con la autorización legal, para que las leyes autoricen a los particulares de llevar lo relativo con las cámaras de comercio encargadas de llevar el registro mercantil y certificar sobre los actos y documentos en él inscritos, entre otras cuestiones. Sin embargo, es necesario anotar que aun cuando es totalmente permitido que los particulares concurran en la gestión del ejercicio de las funciones públicas, ello no conduce a manifestar que todas las funciones de la Rama Ejecutiva puedan ser cumplidas por particulares. Entonces, los particulares no podrán realizar aquellas tareas propias del poder ejecutivo en la medida que invadan las competencias de contenido político o gubernamental. Como son las derivadas, de acuerdo a lo establecido en la C-866/1999, de la figura del presidente como jefe de Estado y de gobierno, como tampoco "las disposiciones de contenido materialmente legislativo o jurisdiccional que ocasionalmente ejercen las autoridades administrativas, pues a la atribución de las mismas a particulares no se refieren las normas constitucionales pertinentes". De otra parte, si bien es cierto que los particulares pueden cumplir funciones públicas, ello no impide el hecho que el Estado ejerza cierto tipo de controles sobre la actividad desarrollada. En el caso que nos ocupa, es patente la situación al permitir a las comunidades organizadas o particulares prestar servicios públicos domiciliarios, y al mismo tiempo el Estado es el encargado de ejercer el control de la regulación, control y vigilancia de los servicios ofrecidos, casos de la Superintendencias. Merece la pena recalcar el hecho que los particulares cumplan funcionen publicas no modifica para nada la esencia de los encargos que se le encomiendan, C-563/1998. 
funciones públicas que se encuentra cumpliendo la entidad privada ${ }^{14}$. Resultado, lo anterior, de la necesidad de asegurar la observancia de los cometidos estatales que le han sido encargados ${ }^{15}$.

Pero esta claridad en la existencia de estas facultades en sede de la entidades que prestan servicios públicos, independiente de su naturaleza, se esfuma en la medida en que se deba responder al interrogante de si el ordenamiento legal vigente entrega un respaldo al ejercicio de la actividad sancionadora de los particulares que prestan este tipo de servicio público.

Como es conocido, el sostén normativo del que se han derivado la potestad sancionadora en este sector han sido las normas: Ley No 142/94, el Decreto reglamentario No 1303/1989, y la Resolución No 108/1997 proferida por la Comisión de Regulación de Energía y Gas; a partir de las cuales se han apoyado las diversas entidades prestatarias del servicio, de todo el territorio nacional, para abrir un sinnúmero de procesos sancionadores los últimos 15 años.

Respaldados en esta normativa se ha venido entregando sustento a todas y cada una de las infracciones y sanciones previstas en los contratos de condiciones uniformes. Sin embargo, se recuerda que para que la actividad sancionadora sea constitucional se debe respetar una serie de máximas, a riesgo de que sea declarada su acción como contraria a la Norma Fundamental.

En este sentido, se revisan a continuación, tres postulados (a saber: reserva de ley, tipicidad e igualdad), que presiden la actividad sancionadora; y su cumplimiento o no en el marco de los servicios públicos domiciliarios. Se resalta la necesidad de recurrir a los principios que informan la actividad sancionadora, en la medida que no existe una ley que se ocupe del poder sancionador de la Administración.

\footnotetext{
${ }^{14}$ En este sentido la Corte Constitucional, en SU- 1010/2008, ha dispuesto que: "la potestad sancionatoria administrativa [...] no está referida de manera exclusiva a las autoridades públicas, entendidas éstas desde el punto de vista orgánico, sino que también puede ser otorgada por la ley a particulares que ejercen funciones administrativas, quienes, [...] actúan como verdaderas autoridades". Frente a ello, resulta pertinente recordar algunas decisiones en las que se ha autorizado a particulares que cumplen funciones públicas a imponer sanciones, en ámbitos diversos a los servicios públicos. Es el caso de los Colegios de Odontólogos y en lo referente con la seguridad social en salud cuando se permite que las entidades que prestan los mencionados servicios sancionen a los usuarios que no cumplan con sus obligaciones y deberes con el sistema.
}

${ }^{15}$ SU-1010/2008. 


\section{Principio de reserva de ley ${ }^{16}$.}

El principio de reserva de ley en materia sancionadora exige que todo ejercicio de la actividad sancionadora deba estar respaldado por una ley. Ello quiere decir que las limitaciones al ejercicio de los derechos y las libertades de los individuos no pueden realizarse de modo arbitrario, sino todo lo contrario deben tener un sólido respaldo de ley o norma jurídica, que tenga la misma entidad ${ }^{17}$.

Este principio puede ser analizado desde, al menos, dos perspectivas, ello se refiere con lo relativo con el tipo de norma que debe respaldar la actividad sancionadora; $y$ de otra parte por la perspectiva referida con la descripción de la conducta típica y su sanción en la norma remitente.

a) Primera perspectiva: el tipo de norma que debe contemplar la potestad sancionadora.

${ }^{16}$ Acerca del principio de legalidad, parte de la doctrina intenta comprenderlo desde una visión integradora, en la que tienen cabida tanto su faceta material como formal. Así: Rivera Temprano, Ezequías, Principios de la potestad sancionadora en la Ley 30/1992. Estudio de la R.J. de las Administraciones públicas y el procedimiento administrativo común (Madrid, Consejo General del Poder Judicial, 1994), II, p. 149; Cano Mata, Antonio, Nuevo entorno de las infracciones y sanciones administrativas tras la entrada en vigor de la Constitución, en Revista Española de Derecho Administrativo 56 (1987), p. 575; SUAY RINCÓN, José, Sanciones administrativas (Bolonia, Real Colegio de España, 1989), pp 171-172; Bergalli, Roberto, Principio de legalidad: fundamento de la modernidad, en Jueces para la Democracia 32 (1998), 59; Moreso, José Juan, Principio de legalidad y causas de justificación en Doxa: Cuadernos de Filosofía del Derecho 24 (2001), p. 525; De Palma Del Teso, Ángeles, El principio de culpabilidad en el Derecho Administrativo sancionador (Madrid, Tecnos, 1996), p. 468; Cano Campos, Tomás, El régimen jurídico-administrativo del tráfico (Madrid, Civitas, 1999), p. 599; Uría Fernández, Francisco, Principios de la potestad sancionadora. Estudios y comentarios sobre la Ley de régimen jurídico de las administraciones públicas y del procedimiento administrativo común (Madrid, Ministerio de Justicia y Ministerio de la Presidencia, 1993), II, p. 149; Domínguez Vila, Antonio, Constitución y Derecho sancionador administrativo (Madrid, Marcial Pons, 1997), p. 270. Otros, en cambio, optan por ejecutar una lectura autónoma de sendas perspectivas del postulado, comprendiendo cada una de las facetas de la máxima como independientes entre sí; pero advirtiendo la existencia de los principios de tipicidad y principio de reserva de ley o de legalidad. En este sentido: Arias Martínez, M. Antonia. La potestad sancionadora de los entes locales y el principio de legalidad (a propósito de la STS de 29 de mayo de 1998, en Revista de Estudios de la Administración Local y Autonómica 280-281 (1999), p. 594; Сово Olvera, Tomás, El procedimiento administrativo sancionador tipo (Barcelona, Bosch, 1999), pp 15-29; MeSEguer YeBra, Joaquín, La tipicidad de las infracciones en el procedimiento administrativo sancionador (Barcelona, Bosch, 2001), p. 14.

${ }^{17}$ Consecuencia de que la ley es la expresión democrática de los asociados, C-827/2001. 
Entonces, para abordar el análisis de los principios que rigen la prerrogativa sancionadora en el ámbito administrativo es necesario cuestionarnos en primer lugar por la reserva de ley exigida para el ejercicio de la potestad sancionadora de la Administración. Es decir, la naturaleza de la disposición normativa que entrega competencias a las autoridades o particulares para que impongan sanciones o que la autoriza para participar en el diseño del ilícito y la sanción administrativa.

Respondiendo a este interrogante tenemos, en primer lugar que son los principios que se aplican en el derecho penal los que se aplican en el campo del derecho administrativo sancionador. Aunque, la intensidad de aquellos va a variar producto de: la potestad reglamentaria de la Administración, los bienes jurídicos en juego, y las finalidades de sendas áreas del derecho ${ }^{18}$.

Aterrizando en el sector de los servicios públicos domiciliarios, como se ha manifestado, han sido tres las normas a partir de las cuales se han derivado tradicionalmente la competencia sancionadora. A saber: la Ley No 142/94, el Decreto reglamentario No 1303/1989, la Resolución No 108/1997 proferida por la Comisión de Regulación de Energía y Gas.

En lo que respecta a la primera disposición resulta claro que cumple con la exigencia del postulado de reserva de ley, pues se trata de una norma dictada por el Congreso de la República. No obstante, si continuamos con el examen de la Ley No 142/1994 esta no lo supera en la medida en que no contempla directamente y sin lugar ambigüedades la competencia sancionadora ${ }^{19}$ a las entidades prestadoras de servicios públicos domiciliarios.

Lo anterior, en razón de que la ley se dedica en exclusiva a los efectos que se le aplican a los usuarios por incumplimiento de sus obligaciones y el modo de realizarse el restablecimiento del servicio, sin establecer expresamente la prerrogativa sancionadora a las entidades que regula. En este sentido, las disposiciones previstas en los artículos 140 y $142^{20}$.

${ }^{18}$ C-145/1993; C-214/1994; C-616/2002; C-720/2006.

${ }^{19}$ En este sentido se pronuncia la SU-1010/2008 al manifestar: "en dicho Estatuto, ni expresa ni implicitamente, el legislador le reconoce facultades a las empresas de servicios públicos domiciliarios para imponer sanciones pecuniarias, por razón del incumplimiento del contrato, y por tanto, tampoco reguló un procedimiento para ejercer dicha facultad. Por lo tanto, de la Ley 142 de 1994 no se deriva la competencia de las empresas de servicios públicos para imponer sanciones pecuniarias a los usuarios".

${ }^{20} \mathrm{El}$ artículo 140 reza: "Suspensión por incumplimiento. El incumplimiento del contrato por parte del suscriptor o usuario da lugar a la suspensión del servicio en los eventos señalados en las condiciones uniformes del contrato de servicios y en todo caso en los siguientes:La falta de pago por el término que fije la entidad prestadora, sin exceder en todo caso de dos (2) periodos de facturación en el evento en que ésta sea bimestral y de tres (3) periodos cuando sea mensual y el fraude a las conexiones, acometidas, medidores 
Frente al requisito de reserva de ley la Corte ha sido clara, exigiendo que la facultad sancionadora se incluya de forma expresa en una norma, sin que exista posibilidad alguna que la autorización legal en mención se pueda deducir por vía de analógica ${ }^{21} \mathrm{o}$ a través de una interpretación sistemática ${ }^{22}$. Producto ello de que las limitaciones a los derechos y las libertades de las personas deben provenir de la voluntad directa de los representantes del pueblo en el Congreso ${ }^{23}$, o en virtud de la facultad extraordinaria entregada al Presidente de la República de acuerdo a lo previsto en el artículo 150.10 de la Constitución ${ }^{24}$.

Continuando con el repaso de las diversas normas que sirven de sostén, tenemos como el Decreto 1303/1989 establecía el monto de las sanciones a imponer en caso de uso fraudulento o no autorizado. Sin embargo, la propia Corte Constitucional de forma expresa ha sostenido que la potestad

o líneas. Es causal también de suspensión, la alteración inconsulta y unilateral por parte del usuario o suscriptor de las condiciones contractuales de prestación del servicio. Durante la suspensión, ninguna de las partes puede tomar medidas que hagan imposible el cumplimiento de las obligaciones reciprocas tan pronto termine la causal de suspensión. Haya o no suspensión, la entidad prestadora puede ejercer todos los derechos que las leyes y el contrato uniforme le conceden para el evento del incumplimiento". A su vez el artículo 142 dispone: "Restablecimiento del servicio. Para restablecer el servicio, si la suspensión o el corte fueron imputables al suscriptor o usuario, éste debe eliminar su causa, pagar todos los gastos de reinstalación o reconexión en los que la empresa incurra, y satisfacer las demás sanciones previstas, todo de acuerdo a las condiciones uniformes del contrato".

${ }^{21}$ En este sentido, resulta pertinente lo previsto en la C-89a/1994 que afirma: "las razones anotadas son aplicables de igual forma a los particulares que se someten a lo dispuesto en el artículo 210 superior, pues si la ley no es estricta en el señalamiento de las funciones a desempeñar, sino que deja al libre albedrio del particular la realización de las mismas, significa que esta persona, investida de la autoridad del Estado, realizaría todo aquello que no estuviere prohibido, en vez de ejercer únicamente lo que le está permitido, desconociendo con ello uno de los pilares fundamentales del Estado Social de Derecho".

${ }^{22}$ T-720/2005; SU-1010/2008.

${ }^{23}$ C-393/2006, "en ningún caso puede transferirle o delegarle al Gobierno o a cualquier otra autoridad administrativa una facultad abierta en esa materia".

${ }^{24} \mathrm{El}$ artículo 150.10 de la $\mathrm{CN}$ da la oportunidad que el presidente de la república dicte decretos con fuerza de ley al disponer que se podrá: "revestir, hasta por seis meses, al Presidente de la República de precisas facultades extraordinarias, para expedir normas con fuerza de ley cuando la necesidad lo exija o la conveniencia pública lo aconseje. Tales facultades deberán ser solicitadas expresamente por el Gobierno y su aprobación requerirá la mayoría absoluta de los miembros de una y otra Cámara. El Congreso podrá, en todo tiempo y por iniciativa propia, modificar los decretos leyes dictados por el Gobierno en uso de facultades extraordinarias. Estas facultades no se podrán conferir para expedir códigos, leyes estatutarias, orgánicas, ni las previstas en el numeral 20 del presente articulo, ni para decretar impuestos". 
sancionadora debe tener en todos los casos un respaldo originario de una ley y no normas dictadas por el ejecutivo ${ }^{25}$.

Por último nos resta manifestar como las resoluciones de las comisiones ya sea del agua y saneamiento básico ${ }^{26}$ o de la regulación de la energía eléctrica y del gas ${ }^{27}$ sí establecen de modo directo la facultad sancionadora que le asiste a las entidades que prestan este tipo de servicios la posibilidad de imponer sanciones administrativas. Aunque no está de más recordar el tipo de norma que contempla la competencia para sancionar.

En este último evento, nos enfrentamos a una disposición administrativa dictada por una Comisión que no posee la entidad suficiente para contemplar de modo autónomo la actividad sancionadora ${ }^{28}$; ya que se trata de una resolución que es producto del desarrollo de la potestad reglamentaria de la Administración ${ }^{29}$; y no de la voluntad de los representantes del pueblo.

Expresado lo anterior, y tal como está el panorama reinante ninguna norma, de las que tienen rango para ello, contempla de viva voz la autorización para que las entidades de servicios públicos, sean estas privadas, publicas o mixtas sancionen a sus usuarios ${ }^{30}$.

b) Segunda perspectiva del principio de reserva de ley: las remisiones normativas.

En el derecho administrativo sancionador no es un imperativo que el legislador ordinario o extraordinario agote lo relativo con las disposiciones sancionadoras. Por el contrario, es totalmente aceptado que las autoridades administrativas participen de la conformación del ilícito administrativo ${ }^{31}$.

${ }^{25}$ La SU-1010/2008 afirma: "ello no significa que la prerrogativa misma pueda ser otorgada por otra autoridad distinta al legislador o que éste pueda habilitar a la Administración para que establezca todos los elementos de su ejercicio. Es evidente que la facultad del ejecutivo para reglamentar la materia exige que exista previamente una ley respecto de la cual ejercer dicha facultad, y que en ésta se establezcan los presupuestos básicos que deben respetarse para su ejercicio".

${ }^{26}$ Resolución No 375/2006, cláusula 27.

${ }^{27}$ Resolución No 108/1997 lo establecía en el artículo 54.

${ }^{28}$ De modo tal como lo describe Ferney Moreno, Luis, Servicios públicos domiciliarios. Perspectivas del Derecho económico (Bogotá, Universidad Externado de Colombia, 2001), p. 42, las Comisiones no tienen facultades legislativas: "en otras palabras, las funciones de las comisiones de regulación no son el ejercicio de facultades legislativas (art. 150.23) ni de ejercicio de potestad reglamentaria (189.11) sino que su función es de expedir actos administrativos de regulación sometidos a la ley, a los reglamentos y a las políticas gubernamentales (art. 208 C.N)".

${ }^{29} \mathrm{~T}-720 / 2005$.

${ }^{30} \mathrm{~T}-720 / 2005$.

${ }^{31}$ García Gómez De Mercado, Francisco, Sanciones administrativas. Garantías, derechos y recursos del presunto responsable (Granada, Comares, 2007), p. 24. 
Consecuencia ello de lo extremadamente técnico o especializados que pueden resultar algunos sectores que están sujetos al control de la Administración ${ }^{32}$; el desarrollo acelerado ${ }^{33}$ que ocurre en ciertos campos que deja atrás el trabajo legislativo; o la previsión excesiva que se le estaría exigiendo al legislador de contemplar todos y cada uno de los supuestos fácticos que pueden colocar en peligro el bien jurídico en cuestión.

De modo tal como lo coloca en evidencia Sánchez Morón: "el Parlamento (los Parlamentos, en un Estado descentralizado) no puede regularlo todo, por lo que las leyes necesitan la colaboración subordinada del reglamento" ${ }^{34}$. Con lo que se permite el empleo de la técnica legislativa denominada colaboración reglamentaria, que consiste en una formación normativa en dos fases ${ }^{35}$. La primera concerniente con la ley remitente y la segunda al reglamento ${ }^{36}$ que se elabora gracias a una habilitación que aquella comprende. Comprendiendo por reglamento: "toda norma escrita con rango inferior a la ley dictada por una Administración Pública" ${ }^{37}$.

Sin embargo, tal invitación a participar de la configuración del binomio infracción/sanción no es una carta blanca para que la Administración o los particulares que cumplen funciones públicas dispongan a su antojo de las infracciones y sanciones ${ }^{38}$. Por el contrario, un comportamiento respetuoso del principio de reserva de ley, tal como ha sido desarrollado por la doctrina de la Corte Constitucional, exige que sea una ley la que establezca los criterios $^{39}$ para definir las infracciones y sanciones en el

\footnotetext{
${ }^{32} \mathrm{C}-860 / 2006$.
}

${ }^{33} \mathrm{Al}$ respecto la C-860/2006 afirma: "en efecto, las normas del derecho bancario y bursátil constantemente deben ajustarse a las variables necesidades de los mercados financieros interno e internacional. De alli que determinadas medidas de carácter normativo pierdan rápidamente su razón de ser y eficacia; incluso pueden resultar inconvenientes $o$ contraproducentes a mediano o largo plazo para los operadores del mercado, afectándose también el interés público. De tal suerte que la regulación de dichos sectores de la economía sea, por naturaleza, mutable, sin ánimo de permanencia”.

${ }^{34}$ SÁnchez Morón, Miguel, Derecho Administrativo. Parte general (Madrid, Tecnos, 2005), p. 180).

${ }^{35}$ González Pérez, Jesús, Comentarios a la ley de régimen jurídico de las administraciones públicas y procedimiento administrativo común (Pamplona, Civitas, 2007), p. 2.824.

${ }^{36}$ Garberí Llobregat, José, El procedimiento administrativo sancionador (Valencia, Tirant lo Blanch, 1998), p. 90.

${ }^{37}$ Parada, Ramón, Derecho administrativo (Madrid, Marcial Pons, 2007), p. 69.

${ }^{38} \mathrm{C}-406 / 2004$.

${ }^{39}$ En este sentido merece la pena reproducir lo previsto en la C-860/2006: " $E l$ principio de legalidad de las sanciones administrativas sólo exige que una norma con fuerza material de ley contemple una descripción genérica de las conductas sancionables, las clases y cuantía de las sanciones, pero con posibilidad de remitir a los actos administra- 
reglamento respectivo ${ }^{40}$.

Entonces, la Corte Constitucional ha manifestado que cuestiones como los supuestos de la infracción administrativa; los sujetos a quienes se dirige el régimen sancionador; las clases de sanciones; los criterios para su imposición; las autoridades encargadas de imponer la sanción; los procedimientos sancionadores $^{41}$; y las remisiones normativas precisas para el supuesto de un tipo en blanco ${ }^{42}$ deben precisarse en una norma con fuerza material de ley y a partir de ahí ser desarrollado por vía reglamentaria.

Sin embargo, estas exigencias que se derivan de la reserva de ley no son cumplidas en el sector los servicios públicos domiciliarios, ya que no existe una ley en esta materia que prevea uno a uno los criterios exigidos por el intérprete constitucional para el respeto del postulado.

Contrariamente a ello, las infracciones y sanciones que se han venido imponiendo obedecen a la iniciativa de la respectiva entidad prestadora del servicio la que de acuerdo a sus necesidades y parecer han venido configurando la infracción con su correspondiente sanción administrativa en los diversos contratos que suscriben con los usuarios. Respaldándose para ello en la habilitación general, que en su entendido, está contemplada en Ley No 142/1994.

De este modo, las conductas típicas y sus correspondientes sanciones administrativas que se han venido imponiendo en el sector de los servicios públicos domiciliarios, los últimos años, encajan perfectamente en una figura prohibida expresamente por la doctrina constitucional como son los reglamentos independientes ${ }^{43}$. Comprendiéndolos como aquellas disposiciones que son dictadas sin ningún tipo de respaldo legal.

\section{Principio de tipicidad.}

Este postulado se concreta en la exigencia de la predeterminación normativa (lex praevia), de las conductas ilícitas y sus sanciones correspondientes que permitan predecir con suficiente grado de certeza ${ }^{44}$ las conductas

tivos la descripción pormenorizada de las conductas reprochables, sin que pueda decirse en este caso que las normas de carácter reglamentario complementan los enunciados legales, pues se trata de una remisión normativa contemplada especificamente por la disposición legal de carácter sancionador".

${ }^{40} \mathrm{C}-835 / 2005$.

${ }^{41} \mathrm{C}-343 / 2006$.

${ }^{42} \mathrm{C}-406 / 2004$.

43 C-597/1996; C-1116/2000; C-829/2002; C-710/2005; C-853/2005; C-343/2006.

${ }^{44}$ Como lo coloca en evidencia NiETo García, Alejandro, Derecho Administrativo Sancionador (Madrid, Tecnos, 2005), p. 305: "la suficiencia de la tipificación es, en definitiva, una exigencia de la seguridad jurídica y se concreta, ya que no en la certeza absoluta, en la predicción razonable de las consecuencias jurídicas de la conducta". 
que se encuentran tipificadas y sus correspondientes respuestas punitivas que deben constar en una ley o norma sancionadora (lex scripta).

En esta medida, la Corte ha admitido que mediante el principio de tipicidad "se desarrolla el principio fundamental "nullum crimen, nulla poena sine lege" ${ }^{45}$, teniendo por finalidad principal que "la descripción que efectue el legislador debe ser de tal claridad que permita que sus destinatarios conozcan exactamente las conductas reprochables" 46 o lo que es lo mismo que el individuo sepa cuál es la conducta castigada con una sanción ${ }^{47}$. Así las cosas, el concepto se concreta en tres elementos que lo integran, es decir, la demanda de lex scripta, lex praevia, lex certa.

Entonces en lo correspondiente con la exigencia de lex scripta ella se corresponde con la frase acuñada de "nulla poena sine lege scripta", que conlleva a que se rechace la aplicación de la costumbre como sustento del ejercicio del poder sancionador del Estado ${ }^{48}$. Costumbre entendida como la práctica generalizada que de acuerdo a unas características, referidas a la constancia y uniformidad, ha adquirido en el seno de una comunidad la fuerza de un precepto o norma obligatoria.

En lo relativo con la exigencia de lex praevia $^{49}$ este mandato implica que los individuos conozcan con anterioridad las conductas que se encuentran prohibidas por el ordenamiento jurídico; así como también las sanciones que se impondrán en caso de que su actuar u omisión encuadre dentro de una infracción administrativa. De modo tal, que se niega toda posibilidad a que alguien sea juzgado conforme a normas sustanciales que definan penas, que no sean anteriores a la actuación que se le imputa ${ }^{50}$. Claro está, ello no tendrá lugar cuando la ley posterior sea más favorable a la existente al momento de lesionar o poner en peligro el bien jurídico en cuestión ${ }^{51}$.

En lo que corresponde con lex certa, el injusto administrativo debe realizarse a través de conceptos jurídicos que permitan predecir, con suficiente grado de claridad ${ }^{52}$ y de modo inequívoco ${ }^{53}$ las conductas que constituyen

${ }^{45}$ C-720/2006.

${ }^{46} \mathrm{C}-99 / 2003$.

${ }^{47}$ Huergo Loras, Alejandro, Las sanciones administrativas (Madrid, Iustel, Madrid, 2007), p. 367.

${ }^{48}$ Vicente Martínez, Rosario de, El principio de legalidad penal (Valencia, Tirant lo Blanch, 2004), p. 36.

${ }^{49} \mathrm{C}-99 / 2003$.

${ }^{50} \mathrm{C}-507 / 2006$.

${ }^{51} \mathrm{C}-922 / 2001$.

${ }^{52} \mathrm{C}-564 / 2000$.

${ }^{53}$ C-796/2004; C-393/2006. 
una infracción y las penas o sanciones aplicables, para que el sujeto sepa a qué atenerse en cuanto a la aneja responsabilidad y la posible sanción ${ }^{54}$.

Para aclarar más el panorama en relación con la extensión o alcance de este concepto la Corte Constitucional ha establecido que la precisión del binomio infracción/sanción implica que se encuentren establecidas cuestiones como el tipo de culpa del infractor, es decir, si es una conducta culposa o dolosa; la intensidad de la culpabilidad del agente, lo que se traduce si la infracción se califica como o leve, grave o gravísima o cualquier otra clasificación que tenga el mismo fin; y la correlativa sanción a la infracción a imponer ${ }^{55}$.

Dicho lo anterior, el órgano constitucional no se opone al empleo de conceptos jurídicos indeterminados ${ }^{56}$, pero determinables ${ }^{57}$; o abiertos ${ }^{58}$,

${ }^{54}$ Lasagabaster Herrarte, Iñaki, Ley de la potestad sancionadora. Comentario sistemático (Bilbao, Lete, 2006), p. 131.

${ }^{55} \mathrm{C}-796 / 2004$.

${ }^{56} \mathrm{Se}$ entiende por conceptos jurídicos indeterminados, se refiere a ellos la C-818/2005 y 564/2900 "aquellos conceptos de valor o de experiencia utilizados por el legislador, que limitan o restringen el alcance de los derechos y de las obligaciones que asumen los particulares o las autoridades públicas. Dichos conceptos lejos de permitir a su interprete escoger libremente por una determinada opción que se considere justa y válida, se encuentran sujetos a una única solución frente al asunto planteado, pues el mismo ordenamiento jurídico a través de los distintos métodos de interpretación, le impone al mismo dicha decisión".

57 "Lo propio de este tipo de conceptos es que, no obstante su indeterminación, los mismos deben ser precisados en el momento de su aplicación. Y tal concreción no responde a una apreciación discrecional del operador jurídico, sino que se encuadra dentro de los parámetros de valor o de experiencia que han sido incorporados al ordenamiento jurídico $y$ de los cuales el operador jurídico no puede apartarse". Y para lograr la determinación, según lo establecido por la C-818/2005, es "imprescindible que la legislación o el mismo ordenamiento jurídico establezcan criterios objetivos que permitan razonable $y$ proporcionalmente concretar las hipótesis normativas".

${ }^{58}$ Se comprende por tipos abiertos, de acuerdo a la C-404/2004: "aquellas infracciones disciplinarias que ante la imposibilidad del legislador de contar con un listado detallado de comportamientos que se subsumen en las mismas, remiten a un complemento normativo, integrado por todas las disposiciones en las que se consagren deberes, mandatos y prohibiciones que resulten aplicables a los servidores públicos". Justificándose, de acuerdo a lo previsto en la C-507/2006, estos tipos abiertos por "la necesidad de salvaguardar el principio de eficiencia de la función pública (C.P. art. 209). Esta Corporación ha reconocido que exigir una descripción detallada en la ley disciplinaria de todos los comportamientos susceptibles de sanción, conduciría en la práctica a tener que transcribir todo el catálogo de deberes, mandatos y prohibiciones que se imponen a los servidores públicos en las distintas normas jurídicas, traduciéndose dicha exigencia en un obstáculo para la realización coherente, ordenada y sistemática de la función disciplinaria $y$ de las finalidades que mediante ella se pretenden". 
siempre que el reenvío normativo permita al operador jurídico precisar sin lugar a dudas el alcance de la conducta reprochable y de la sanción correspondiente ${ }^{59}$. Aunque ello no admite la utilización de conceptos indeterminables ${ }^{60}$, o inconcretos ${ }^{61}$, imprecisos o difusos ${ }^{62}$. Pues estos entregan la definición del comportamiento prohibido a la discrecionalidad de las autoridades, que podrían valorar y sancionar libremente la conducta sin referentes normativos precisos ${ }^{63}$.

Una vez expresado los lineamientos más sobresalientes del principio de tipicidad, su concepto, alcances y limitaciones, es evidente como el estado actual de las cosas en materia de servicios públicos domiciliarios no cumple con las exigencias derivadas de la máxima.

En este entendido, basta observar como ninguno de los elementos que integran el concepto mismo de tipicidad es cumplido. Es así como en el caso de la exigencia de lex scripta y lex praevia, estos requisitos no se cumplen en tanto que ninguna ley dictada por el Congreso contempla de viva voz los elementos que definen las infracciones y las sanciones del binomio punitivo en sector en concreto de los servicios públicos domiciliarios.

Recordamos que el sostén normativo del que se ha derivado tradicionalmente la potestad normativa no tiene ninguna mención directa sobre el particular y sostiene simplemente que: "para restablecer el servicio, si la suspensión o el corte fueron imputables al suscriptor o usuario, éste debe eliminar su causa, pagar todos los gastos de reinstalación o reconexión en los que la empresa incurra, y satisfacer las demás sanciones previstas, todo de acuerdo a las condiciones uniformes del contrato" 64 .

En lo que corresponde con la demanda de lex certa tampoco se satisface en razón que la Ley No 142/1994 no ha contemplado directamente aquellas cuestiones mínimas exigidas para que sea cumplida esta exigencia. Conduciendo a que se deje en manos de las diversas entidades prestadoras de servicios públicos domiciliarios la configuración normativa que hasta el momento se ha venido realizando a su antojo.

${ }^{59} \mathrm{C}-507 / 2006$.

${ }^{60} \mathrm{C}-475 / 2004$.

${ }^{61}$ En esta línea se pronuncia la providencia C-819/2006 que afirma: "por el contrario, si el concepto es a tal punto abierto, que no puede ser concretado en forma razonable, entonces dichos conceptos desconocen el principio de legalidad, pues la definición del comportamiento prohibido queda abandonada a la discrecionalidad de las autoridades administrativas, que valoran y sancionan libremente la conducta sin referentes normativos precisos".

${ }^{62} \mathrm{C}-99 / 2003$.

${ }^{63} \mathrm{C}-530 / 2003$.

${ }^{64}$ Ley No 142/1992, art. 142. 


\section{Principio de igualdad.}

El hecho que la potestad sancionadora que ejerza un particular que presta servicios públicos no tenga un soporte legal que respalde la limitación de derechos y libertades de los individuos; y establezca los parámetros, es decir, los rangos mínimos y máximos tanto para las infracciones como para las sanciones para el ejercicio del poder punitivo, conduce irremediablemente a otra reflexión y es la relativa con la lectura que debe dársele al principio de igualdad.

Esta máxima tiene sustento constitucional en el artículo 13 de la Norma Fundamental que establece: "todas las personas nacen libres e iguales ante la ley, recibirán la misma protección y trato de las autoridades y gozarán de los mismos derechos, libertades y oportunidades sin ninguna discriminación". Lo que se traduce en "tratar de un modo igualitario a quienes se encuentren vinculados por un elemento esencial"65.

Sin embargo, derivar el respeto del principio de igualdad del escenario al que nos enfrentamos resulta bastante complicado, en tanto que las diversas instituciones que prestan el servicio público domiciliario en el país están imponiendo sanciones diversas, y aun de la misma naturaleza, pero con una intensidad distinta, a los individuos que realicen una misma conducta. Y qué decir de la posibilidad que les asiste de tipificar de cualquier modo las conductas a su antojo.

Entonces, producto de la libre configuración de infracciones y sanciones que se han arrogado las entidades que presentan servicios públicos domiciliarios, que tienen lugar en los contratos de condiciones uniformes, es totalmente factible que un habitante de cualquier ciudad de nuestro país que haya cometido una misma conducta sea sancionado con medio salario mínimo; mientras que otra persona de la misma ciudad y usuaria del mismo servicio, pero prestado por otro operador sea sancionado con el equivalente de dos o tres salarios mínimos legales vigentes. ¿Será acaso que esta situación no es violatoria del principio de igualdad en el marco del ejercicio del poder sancionador de la Administración?; o ¿es que existen circunstancias objetivas, razonables, proporcionadas que justifiquen la diferenciación? ${ }^{36}$.

A lo que contestamos rotundamente que no. Lo anterior, en virtud de que la definición de las infracciones y las sanciones es un asunto que debe conocer en exclusiva el Congreso de la República, en tanto define los parámetros a partir de los cuales la Administración, en desarrollo de la

${ }^{65}$ Carrasco Quiroga, Edesio, El artículo 42 de la ley de concesiones: justicia y proporcionalidad de la sanción, comentario a la sentencia del Tribunal Constitucional de fecha 26 de diciembre de 2006, en Revista Chilena de Derecho 35 (2008) 1, p. 198.

${ }^{66} \mathrm{C}-421 / 2008$. 
potestad reglamentaria, puede llegar a completar el binomio infracción/ sanción $^{67}$.

De este modo, le estará solamente autorizado al legislador, por intermedio de su capacidad creadora de normas generales, impersonales y abstractas, el que tendrá en exclusiva la capacidad para limitar por igual los derechos y libertades; y al mismo tiempo la posibilidad de imponer obligaciones a los asociados, con el fin de salvaguardar los efectos derivados del principio de igualdad como es: "igualdad ante la ley" ${ }^{68}$.

Así las cosas, de ninguna manera, le estaría permitido a la Administración o en su caso a los particulares, que cumplen funciones administrativas, imponer sanciones por infracciones que no gozan de un sustento legal, pues como advertimos no solo se viola lo establecido en los principios de reserva de ley y tipicidad, sino que al mismo tiempo desconoce el principio según el que todos nos encontramos en pie de igualdad $^{69}$ ante el poder punitivo del Estado ${ }^{70}$.

En este sentido se ha manifestado directamente la Corte Constitucional al expresar que: "la garantía constitucional del principio de legalidad impone al legislador la obligación de definir previa, taxativa e inequivocamente las conductas consideradas como reprochables y las sanciones en las que incurrirá quien cometa alguna de las conductas prohibidas, pues sólo de esa manera el principio de legalidad cumple verdaderamente su función garantista y democrática, protege la libertad de las personas y asegura la igualdad ante el poder punitivo estatal'71.

Entonces, es difícilmente defendible el hecho que se puedan imponer sanciones diversas, por todo el territorio nacional, por la comisión de un mismo hecho sin que existan razones que justifiquen la respectiva discriminación.

De este modo, la Corte Constitucional ha manifestado que una discriminación es válida únicamente en la medida en que la discriminación o el trato diferenciado sea adecuado para el logro de un fin constitucionalmente válido; necesario, en el sentido de que no exista uno menos oneroso ${ }^{72}$, para alcanzar un fin; y proporcionado ${ }^{73}$, es decir: "que no se sacrifiquen valores,

${ }^{67} \mathrm{C}-290 / 2008$.

${ }^{68} \mathrm{~T}-30172004$.

${ }^{69}$ BANDRÉS SÁNChEZ-CruZAT, José, Las garantías constitucionales del procedimiento administrativo sancionador (Madrid, Consejo Nacional del Poder Judicial, 1994), p. 128.

${ }^{70} \mathrm{C}-406 / 2004$.

${ }^{71} \mathrm{C}-653 / 2001$. Las negrillas y subrayado no son del texto original.

${ }^{72} \mathrm{C}-780 / 2001$.

${ }^{73} \mathrm{C}-421 / 2008$. 
principios o derechos" ${ }^{34}$. No obstante, de acuerdo con el escenario al que nos enfrentamos no es posible ni siquiera emplear el "test" de proporcionalidad, ya que ni siquiera se cuenta con una norma a partir de la que podamos sustentar la discriminación existente.

\section{CONCLUSIONES}

Una vez que se han analizado los aspectos más importantes de las prerrogativas entregadas por el ordenamiento jurídico al sector de los servicios públicos domiciliarios; y de modo concreto la viabilidad constitucional de las sanciones impuestas, se concluye que:

a) El marco normativo del sector de los servicios públicos domiciliarios tuvo una transformación radical con la promulgación de la Constitución de 1991, ello se refleja de diversos modos, como son: la introducción del régimen de tarifas que tuviera en cuenta los costos, la posibilidad que particulares presten el servicio, o la viabilidad de realizar un control social a las instituciones que gestionan el servicio.

b) Para dar cumplimiento a lo establecido en la Constitución de 1991 el legislador ordinario dicta la Ley No 142 de 1994 . Norma que contempla una serie de prerrogativas a las entidades que ofrecen el servicio. Muestra de ello son las facultades reconocidas para imponer servidumbres, regirse por normas de derecho privado en materia de contratación, o la posibilidad de realizar inspecciones a los usuarios del servicio con el fin de verificar las desviaciones significativas de los consumos.

c) La Ley No 142 de 1994 no realiza ninguna mención directa sobre la potestad sancionadora de las entidades que gestionan los servicios públicos domiciliarios.

d) La falta de un respaldo legal de la actividad sancionadora conlleva a que el ejercicio de esta potestad ejercida por las entidades prestatarias del servicio no encuadre en el marco constitucional del debido proceso aplicable a los expedientes administrativos sancionadores. Con ello se hace referencia, entre otros a los principios de reserva de ley, tipicidad e igualdad.

E) El principio de reserva de ley que informa la actividad sancionadora administrativa no es respetado por el marco legal existente. En este sentido, es necesario que una ley, dictada por el Congreso, contemple de viva voz la facultad para diseñar infracciones y sanciones; y del mismo modo la facultad para el ejercicio de esta actividad.

f) El principio de tipicidad igualmente no es satisfecho por el sistema

${ }^{74} \mathrm{C}-780 / 2001$. 
normativo actual, dado que ninguno de los presupuestos que integran el postulado resultan cumplidos por la normativa sectorial. De acuerdo al escenario presente, existe una libertad, contraria a la Constitución, para contemplar infracciones y sanciones sin topes señalados en ninguna ley.

g) La falta de un marco preciso para el ejercicio de la actividad sancionadora conlleva a la violación de otro principio que dirige el ejercicio punitivo, como es el principio de igualdad. En este sentido, al no existir parámetros contemplados en una ley para las infracciones y sanciones las entidades prestadoras del servicio pueden diseñar, en sus contratos de prestaciones uniformes, infracciones y sanciones a su antojo y con ello introducir discriminaciones violatorias al principio de igualdad ante el poder punitivo de la Administración.

h) A pesar que el panorama normativo actual no es respetuoso de los principios que deben presidir la actividad sancionadora de la administración y por tanto su ejercicio es contrario al marco constitucional, ello no es óbice para que el legislador ordinario dicte, en cualquier momento, una norma en materia de servicios públicos domiciliarios en la que se dé respuesta y respaldo al ejercicio de la actividad sancionadora. Y de este modo, autorizar las sanciones impuestas por las empresas, sin distinción del origen del capital, a los usuarios del servicio.

[Recibido el 11 de agosto y aprobado el 21 de septiembre de 2009].

\section{BIBLIOGRAFÍA}

Arias Martínez, M. Antonia, La potestad sancionadora de los entes locales y el principio de legalidad, a propósito de la STS de 29 de mayo de 1998, en Revista de Estudios de la Administración Local y Autonómica 280-281 (1999).

Atehortua Ríos, Carlos, Servicios públicos domiciliarios proveedores y régimen de controles (Bogotá, Universidad Externado de Colombia, 2006)

BANDRÉs SÁNCHEZ-CRUZAT, José, Las garantías constitucionales del procedimiento administrativo sancionador (Madrid, Consejo Nacional del Poder Judicial, 1994).

Bergalli, Roberto, Principio de legalidad: fundamento de la modernidad, en Jueces para la Democracia 32 (1998).

Bermejo Mera, José, Derecho Administrativo.Parte especial (Madrid, Civitas, 2001).

CANo CAMPOS, Tomás, El régimen jurídico-administrativo del tráfico (Madrid, Civitas, 1999).

Cano Mata, Antonio, Nuevo entorno de las infracciones y sanciones administrativas tras la entrada en vigor de la Constitución, en Revista Española de Derecho Administrativo 56 (1987).

Carrasco Quiroga, Edesio, El artículo 42 de la ley de concesiones: justicia y proporcionalidad de la sanción, comentario a la sentencia del Tribunal Constitucional de fecha 26 de diciembre de 2006, en Revista Chilena de Derecho 35 (2008) 1. 
Carretero Pérez, Adolfo, Derecho Administrativo sancionador (Madrid, Editoriales de Derecho Reunidas, 1995).

Cobo Olvera, Tomás, El procedimiento administrativo sancionador tipo (Barcelona, Bosch, 1999).

De Palma Del Teso, Ángeles, El principio de culpabilidad en el Derecho Administrativo sancionador (Madrid, Tecnos, 1996).

DEVIS Isaac, Aspectos constitucionales de los servicios públicos y las telecomunicaciones en Colombia (Bogotá, Universidad del Rosario, 2007).

Domínguez VILA, Antonio, Constitución y Derecho sancionador administrativo (Madrid, Marcial Pons, 1997).

Ferney Moreno, Luis, Servicios públicos domiciliarios. Perspectivas del derecho económico (Bogotá, Universidad Externado de Colombia, 2001).

GARBERÍ LlOBREGAT, José, El procedimiento administrativo sancionador (Valencia, Tirant lo Blanch, 1998).

García De Enterría, Eduardo, Curso de Derecho administrativo (Madrid, Civitas, 2004).

García Gómez De Mercado, Francisco, Sanciones administrativas. Garantías, derechos y recursos del presunto responsable (Granada, Comares, 2007).

GONZÁLEZ PÉREZ, Jesús, Comentarios a la ley de régimen jurídico de las administraciones públicas y procedimiento administrativo común (Pamplona, Civitas, 2007).

Huergo Loras, Alejandro, Las sanciones administrativas (Madrid, Iustel, Madrid, 2007).

LEAL, Hildebrando, Derecho de sociedades comerciales (Bogotá, LEYER. 2006).

MATIAS, Sergio, Los servicios públicos domiciliarios en Colombia. Análisis socio-jurídico (Bogotá, Universidad Libre. Centro de Investigaciones Socio-Jurídicas, 2001).

Meseguer Yebra, Joaquín, La tipicidad de las infracciones en el procedimiento administrativo sancionador (Barcelona, Bosch, 2001).

Moreso, José Juan, Principio de legalidad y causas de justificación en Doxa: Cuadernos de Filosofía del Derecho 24 (2001).

Nieto García, Alejandro, Derecho administrativo sancionador (Madrid, Tecnos, 2005.

Palacio Mejía, Hugo, El derecho de los servicios públicos. Derecho Vigente S. A. (Bogotá, Bancol, 1999).

ParadA, Ramón, Derecho administrativo (Madrid, Marcial Pons, 2007).

Penagos, Gustavo, Empresas estatales. Proyección al siglo XXI (Bogotá, Doctrina y Ley, 2000).

Rivera Temprano, Ezequías, Principios de la potestad sancionadora en la Ley 30/1992. Estudio de la R. J. de las Administraciones públicas y el procedimiento administrativo común (Madrid, Consejo General del Poder Judicial, 1994), II.

SÁnchez Morón, Miguel, Derecho administrativo. Parte general (Madrid, Tecnos, 2005).

Suay Rincón, José, Sanciones administrativas (Bolonia: Real Colegio de España, 1989).

Uría Fernández, Francisco, Principios de la potestad sancionadora. Estudios y comentarios sobre la Ley de régimen jurídico de las administraciones públicas y del procedimiento administrativo común (Madrid, Ministerio de Justicia y Ministerio de la Presidencia, 1993), II. 
452 Revista de Derecho XXXIII (2 ${ }^{\text {do }}$ Semestre de 2009) María RamíreZ - Judith Echeverría

VARELA BARRIOS, Edgardo, Las privatizaciones en Cartagena y Barranquilla. Un paradigma mercantilista en la gestión de los servicios públicos domiciliarios en Colombia, en Revista Pensamiento y Gestión 23 (2007).

Vicente Martínez, Rosario de, El principio de legalidad penal (Valencia, Tirant lo Blanch, 2004). 